\title{
Schema Enhancement as a Veritable Tool for the Promotion of Students' Reading Comprehension and Reading Comprehension Achievement
}

\author{
Iduma Ogbonnaya-Iduma Angela
}

Ebonyi State University, Abakaliki, Nigeria

\author{
Doi:10.5901/mjss.2014.v5n26p161
}

\begin{abstract}
Reading is an important aspect of the language skills which deals with the interaction between the reader and the text. This successful interaction results in reading comprehension. Scanty background knowledge (schema) usually affects reading comprehension and, reading comprehension failure gives rise to poor reading comprehension achievement. To promote reading comprehension and achievement, the students schema needs to be improved, and to achieve this, Advance organizers which is an introductory instructional strategy has to be employed. This is a very strategic tool for schema enhancement and its components are graphic organizers which incorporate concept webbing or mapping, concept enhancement routines, and related organizers. This can be meaningfully introduced to the students through the pre-reading strategy to improve on the students schema before comprehension tests are given. This study, therefore, examines schema enhancement as a tool for the promotion of student's reading comprehension and achievement.
\end{abstract}

Keywords: Schema, Enhancement, Reading Comprehension, Achievement

\section{Introduction}

Reading is very vital to everyone, especially to students who want to excel academically. This owes to the fact that every text requires reading for its contents to be accessed. Agwu (2011) rightly points out that educational advancement is facilitated by the students ability to read and understand texts. In the same vein, Anderson (2011) reveals that reading is important for a student to successfully complete all college level courses.

For reading to be meaningful, it must be accompanied with comprehension. Maduabuchi (2005) shows that meaning cannot be divorced from reading: they are like two sides of a coin, each carrying the other along. It is in the process of reading that the writer transfers meaning to the reader. Thus, the reading comprehension according to Anderson (2004) is the interactive mental process between a reader's linguistic knowledge, knowledge of the world and knowledge about a given topic. The wealth of experience of the reader is very important for comprehension to take place. Pressly and El-Dinary (1995) indicate that comprehension rests on two vital information strategies: that which is got from the text and that which is realized in the reader's memory. Here, it is seen that the residual knowledge of the reader ignites comprehension. Thus, the schemata of the past experiences and prior knowledge in the readers' memory are critical in reading comprehension Ausubel (1960).

\section{The Concept of Reading / Reading Comprehension}

English language scholars like Carrel in Matthew, Thomas, Manzo, Anthony \& Casale (2005), Anderson (2011), Carr (2010), Ekpu (2005), Omojuwa (2005), Udosen and Ukpak (2005) have given various definitions of reading as well as reading comprehension. Reading is an interaction between the reader and the text (Matthew, Thomas, Manzo, Anthony\& Casale 2005).Carr (2010) similarly defines reading as an interactive process. Reading is the process of combining textual information a reader brings to a text with a previous knowledge. The reading process is not simply a matter of extracting information from the text, rather it is one in which reading activates a range of knowledge in the reader's mind that he or she uses, and that in turn may be defined and extended by the new information supplied by the text. Reading is a dialogue between the reader and the text. This is obvious because meaning cannot be divulged from information. Behind every information is meaning which the reader gets in the course of reading.

Anderson (2011) holds that reading is not a passive but rather an active process, involving the reader in an ongoing interaction with the text. Reading is therefore an active process. Reading is further expanded to meaning seeking, information processing (how language and thought interact) as well as the sociolinguistic aspects (language operating in a social context including writers as readers). 
Similarly, Ekpu (2005), Omojuwa (2005), Udosen and Ukpak (2005) have the same view that reading is getting meaning from a text or from symbols that represent the spoken language. Reading, therefore, is interacting with the language that has been coded into print. Maduabuchi (2005:66) conceives reading as "a process and not a product" which characterize an ongoing activity that begins long before the child gets to school and continues to develop through life. Reading involves learning and it equally incorporates the individual's linguistic knowledge and can positively or negatively be affected by non-linguistic internal or external variables. Richgels in (Maduabuchi 2005) therefore notes that reading comprehension is the result of a successful interaction of a reader with a text. This goes to strengthen the fact that reading has to be a part and parcel of students' life for a good academic performance.

Contrary to various definitions of reading, Potter (2011) is of the opinion that reading is not synonymous to deriving meaning from the printed page; in fact they assert that there is no meaning at all on a printed page. To be found there are only lines and curves that we happen to call letters from which we build words. According to them, comprehension will not be found on the printed pages but in the mind of the readers who read the words. It is difficult to agree with these researchers because both the printed pages and the readers mind work simultaneously to achieve comprehension.

From the view of Potter (2011), it is clear that experience is necessary for the comprehension of a text. Then, what is comprehension? Anderson (2011) defines comprehension as an interaction of new information with old knowledge. Similar to the views of Potter (2011), Anderson (2011) equally analyzes another type of interactive model of reading, namely a schema-theoretical model. The work shows how reading comprehension involves interaction between old and new information. It equally focuses on how the readers schemata, or knowledge already in memory function in the process of interpreting new information and allowing it to enter and become a part of the knowledge store. Abioye (2010) equally upholds the same view. To him reading comprehension is processing written language to get ideas, relating ideas to experience, organizing ideas, evaluating ideas and utilizing ideas. For this to be possible, the reader equally must have intelligence, language and experience. Imam (2004) also posits that comprehension is building bridges between the known and the new. Imam's view seem convincing because the reader cannot but interpret and understand what he/she reads in accordance with the wealth of related knowledge about the topic under discussion.

Akpama, Egong and Akwa (2005) see reading and comprehension as complementary. In their view, comprehension means understanding and making sense of what is being read or heard. They establish that effective reading comprehension for students in the content area is very vital and that reading comprehension questions to be answered by students in the examination help to ascertain their level of understanding at the vocabulary, grammar and content levels. These are important areas in the English language and lack of understanding in any of these areas contributes greatly to the mass failure of students in the English language examinations especially in the reading comprehension tests. To aid students' understanding in reading comprehension as well as their achievement, their schema has to be properly built and enlarged.

\section{What is Schema?}

Schema (singular) is the background knowledge stored by the reader which facilitates the understanding of a text. Ajideh (2003) indicates that schemata (plural) are important for English as a foreign language and English as a second language (EFL/ESL) readers. The background knowledge accumulated by the reader over a period of reading or as a result of cultural and linguistic interactions all combine to give meaning to what is read. If the reader lacks appropriate schemata or fails to activate them, comprehension may be hindered.

The schema theory is described as a process through which readers combine their own background knowledge with the information in a text for better understanding (Agwu 2011). This means that the more related the reader's schemata and the text, the more comprehension occurs. When students are familiar with the topic of the text they are reading (content schema), aware of discourse level and structural make-up of the genre of the text (formal schema) and skillful in the decoding of features needed to recognize words and realize how they fit together in a sentence (language schema), they are well equipped for comprehension to take place in reading (Shen 2004; Pulido 2004). Thus, the importance of schema in reading comprehension cannot be overemphasized. It goes a long way to determine the success or failure of the reading task, as well as comprehension. Ajideh (2003) reveals that schemata can be activated to aid comprehension. Any schemata that is allowed to lie dormant might not benefit the reader. In any reading process, it is expected that the reader relates the new information with his schemata for comprehension to take place. Daniel and SPED (2005) indicate that in a situation where the reader refuses to activate his schemata in any reading task, comprehension failure may occur.

Bransford (2004) describes schemata as "packets of information stored in memory representing general knowledge about objects, situations, events or actions." The whole lot of experiences acquired in life no matter how it 
came about, forms the reader's schemata. "A schemata, according to Ajideh (2003:4)" "is a hypothetical mental structure for representing generic concepts stored in memory. It is a set of framework or plan or script. Schemata are created through experiences with people, objects and events in the world. When we encounter something repeatedly, such as a restaurant, we begin to generalize across our restaurant experiences to develop an abstracted generic set of expectations about what we will encounter in a restaurant."

The schemata theory indicates that three main areas of schemata connected to reading exist: linguistic schemata formal schemata and content schemata. Grasser \& Golding (1991) give a vivid explanation of these three areas:

\subsection{Linguistic Schemata}

Students need to have a good knowledge of the language of which the text to be read is presented. Thus abundant background knowledge also includes the ability of the reader to recognize sounds and letters of and other components of texts. Linguistic schemata is the knowledge of letters and their accompanying sounds, whether they are in cluster or alone. It also refers to the ability to make a prediction through knowledge of syntax as well as the word or words that follow. They are the foundation for other schemata and they are absolutely important to decode and understand in the process of reading. According to Grasser \& (2007), the more linguistic schemata are in the reader's mind, the faster he can gain information and the better he can comprehend.

\subsection{Formal Schemata}

Equally, formal schemata is the knowledge of rhetorical matter as well as the arrangement and the presentation of the forms in which the information in a text is written. The speed by which the reader processes the text is influenced by the familiarity of the structure of the text.

\subsection{Content Schemata}

Content schemata, on the other hand, refers to the background knowledge the reader has concerning the topic being read (Agwu 2011). It showcases the reader's familiarity of the topic based on the previous experience. Content schemata also helps the reader to relate what is being read to his socio-cultural settings. They involve topic familiarity, cultural knowledge and previous experience of an area of life. Readers with greater background knowledge are in the position to comprehend and remember what is read better. Any deficiency in any of these schemata explained above, will amount to a reading comprehension deficit. This goes to strengthen the fact that the problems students encounter in reading derives a lot from poor background knowledge. The experiences acquired in life as well as one's world knowledge are stored in the brain hierarchically and the intercourse of the knowledge stored with the new schema gives birth to reading comprehension.

\section{Factors Affecting Reading Comprehension}

Many factors influence the second language (L2) learner's reading comprehension which invariably affects his/her reading comprehension achievement. These factors are: vocabulary size, syntactic and semantic knowledge, and background knowledge (Agwu 2011).

\subsection{Vocabulary Knowledge}

Vocabulary knowledge, or knowledge of word meaning, to a large extent, plays a very important role in reading comprehension. To comprehend the written text, the reader must distinguish the meaning of most words they encounter. The reason is that some texts contain highly technical and multisyllabic words that students usually find difficult to decode. To a very high degree, vocabulary knowledge has been recorded to be the strongest predictor of successful comprehension of content area reading among secondary school students (Maduabuchi 2005). Although vocabulary knowledge is not the only factor contributing to text comprehension, it can be viewed as an essential and accurate predictor of reading ability of a second or foreign language learner, and also has a direct impact on his comprehension ability. Nevertheless, vocabulary scientists have not clearly agreed on the vocabulary size the L2 and EFL learner needs to achieve comprehension in reading printed text. 


\subsection{Syntactic and Semantic Knowledge}

Syntactic and semantic knowledge is another influential factor in reading comprehension. Having recognized the words in a text, readers ought to apply their syntactic and semantic knowledge to extract the author's intended message from the text (Agwu 2011). However, skilled and less skilled readers also vary in their ability to make use of syntactic knowledge which plays a function in the meaning construction and interpretation of texts. Anderson (2011) believes that syntactic knowledge is significant for two reasons: one can use a word or express the meaning of a sentence plainly with the aid of grammatical structures and rule of syntax. Next, analyzing the syntactic structure of a sentence can be useful to identify and recognize words. Semantics refers to word meaning. The knowledge of words quickly and correctly are likely to lead to comprehending texts more easily. Consequently, inefficient semantic access may be a result of decoding problems, thereby leading to comprehension failure during the reading process which also affects reading comprehension achievement.

\subsection{Background Knowledge}

Background knowledge, also known as residual knowledge, prior knowledge, knowledge in store (Maduabuchi 2005), which has been summarily referred to as schemata, wields overwhelming influence on reading comprehension. Agwu (2011) describes background knowledge as an individual's life experiences and the knowledge of the world acquired through one's life. Some students have scanty background knowledge and perform poorly in reading comprehension while some others who have more encounter with print materials, more experiences as a result of social and linguistic interaction and pre-reading instructions, perform better in reading comprehension.

\section{Ways of Improving Reading Comprehension}

Many ways can be used to enhance the students' reading comprehension and achievement. They include:

\subsection{Decoding}

To improve the students' reading comprehension, the students need to be taught how to decode appropriately. To achieve this, word recognition skills must be properly developed to the point of fluency. Students' recognition of words in comprehension passages facilitate their understanding. The need to have knowledge of sounds and letters and how they can be combined to pronounce words is very vital in the improvement of reading comprehension.

\subsection{Vocabulary Development}

Vocabulary development is another efficacious way of improving reading comprehension. The knowledge of vocabulary makes a passage simpler and subsequently facilitate understanding. Pressely (2007) indicates that studies show that children who received instruction in vocabulary performed better in reading comprehension more than their counterparts who did not. Successful readers are more efficient at gaining unfamiliar word meanings from texts when they have greater existing vocabulary, more experience using context dues and greater background knowledge. (Anderson 2011) reveals that this background knowledge plays a preponderant role in the comprehension of a text. There must be schemata for the syntax and the vocabulary at the disposal of the reader to trigger speedy comprehension.

\subsection{Extensive Reading}

Although teaching vocabulary is helpful it does not underscore the fact that students equally learn new words in text worlds without really being formally taught. Thus students should be encouraged to read extensively (Agwu 1994) as many vocabularies they acquire are learnt incidentally. In addition, Extensive reading is a very effective means of enhancing schema since it adds to the sharpening of the cognitive structures of the brain. Daniel and SPED (2005) reveal that psychologists believe that prior knowledge is stored in the cognitive structures of the brain. As students embark on substantial extensive reading, they would be properly equipped to relate what they already know to the numerous texts they are reading. At the end of any extensive reading assigned, they should be asked elaborate questions to determine their level of reading comprehension. 


\section{Schema Enhancement}

Schema enhancement is the strongest means of improving reading comprehension and achievement. It is the building of background knowledge in order to facilitate reading comprehension. There is a serious need to enhance the students' schema in order to boost their reading comprehension and achievement. Many ways can be employed to achieve this:

\subsection{Advance Organizers}

This was developed by Ausubel (1960) in a research on introductory instructional strategy that would aid the activation of schema or pior knowledge. The organizers provide mental scaffolding to learn new information (Hassard 2005) making it easier to understand, learn, retain and recall.

Cognitive psychologists believed that all of a person's prior knowledge was stored in the cognitive structures of the brain. Therefore, in order for the acquisition of new knowledge to take place and to be meaningful, prior knowledge needed to be activated within these structures by means of an introductory instructional strategy (Kalmes 2005). Ausubel (1960) therefore developed the new strategy that he termed advance organizers. It provides a kind of "mental scaffolding to learn new information" (Hassard, 2005:1), making learning, retaintion and recalling very easy. Advance organizers that build schema by providing new information are called expository organizers. When the advance organizers helps students to recall prior knowledge by activating existing schema, they are called comparative organizers (Kalmes 2005). Anderson (2004) indicates that advance organizers are excellent ways to activate and build schema before the actual learning of new material by students. This can be presented through the pre-reading strategy.

There are many types of organizers that help in building the students schema. Advance Organizers, Graphic organizers, concept Enhancement Routines, concept Anchoring Routine, concept webbing or Mapping, and some others. These organizers in one way or the other, are used as pre-reading tools to enhance reading comprehension and achievement.

Ausbel (1960) records that when organizers are used as pre-reading tools, they help in establishing a link between pre-reading information and a readers' existing schema.

\subsection{Graphic Organizers}

Graphic organizers which is a component of advance organizers uses a hierarchical visual display of various graphs to map out the main concept and the supporting material (Branford 2004). Anderson (2004) indicates that graphic organizers immensely facilitate comprehension.

\subsection{Concept Enhancement Routines}

Concept Enhancement routines which incorporate concepts diagrams and concept mastery routines when used to introduce new material to students provide positive responses. Concept webbing or mapping equally enhances student's comprehension. It is more pectoral in nature and it also increases the students understanding by providing a skeletal map that increases the students' ability to link new concepts with prior knowledge therefore increasing retention and recall (Hassard 2005).

\subsection{Pre-reading Strategy}

Pre-reading Strategy aims at preparing the students adequately for enhanced reading comprehension before any reading task is assigned. It is an introductory instruction strategy which employs various components of Advance Organizers to build schema. Pre-reading strategy equally uses discussion to enhance the students' schema (Bransford 2004). Discussion is very important at all stages of the learning process, but at the early stage, teacher led discussion is part of activating prior knowledge and building new schema to relate to topics to be presented (Eisenwine 2000). The use of questioning should also be employed. Simply asking students questions about experiences that they have had can be used to relate prior knowledge to the new concepts in the upcoming material (Branford 2004). The students can also be given topics to be searched out in the web and then discuss the topics in the class as part of the pre-reading strategy. This helps to ignite the students' prior knowledge thereby enhancing his/her schema. 


\section{Conclusion}

To overcome the poor performances usually encountered in reading comprehension, the schema needs to be enhanced. The major ways of achieving this is by teaching the students to decode correctly, improving on their semantic and syntactic knowledge, building their vocabulary, encouraging them to read extensively, and above all, employing the use of the Advance Organizers. The pre-reading strategy would also be an efficacious means of getting the students schema enhanced. When these are done, students' reading comprehension and reading comprehension achievement would be greatly improved.

\section{References}

Abioye, T. (2010).Integrating Reading and Writing Skills in Nigerian Schools Using News-paper Texts.Papers in English and Linguistics (PEL). (OAU, Ife). 11, 44-53.

Agwu S.N. (2011). Effect of Accuracy level and Text Type on secondary school students' use of syntactic and semantic Cues in Reading comprehension.EBSU Journal of Society. Ebonyi State University: Abakaliki.

Agwu, S. N. (1994). The relationship between reading interest and reading comprehension in Nigerian secondary schools. Readings in Tertiary Teaching (Joof A.E) and Ikwumelu \&Agwu S.N. eds) Owerri; Whyte publishers.

Ajideh, P. (2003). Schema theory-based pre-reading tasks: A neglected essential in the ESL reading class. The Reading Matrix, 3(1).

Akpama, G. E., Egong, I. A. \& Akwa, A. M. (2005). Reading for effective comprehension in junior secondary schools: Implications for guidance and counselling. Journal of Applied Literacy and Reading 2. Port Harcourt: Double Diamond.

Anderson, C \& Pearson D (2004).A schema theoretic view of basic processes in reading comprehension. Handbook of Reading Research.

Anderson, J. (2011). What are the Factors Affecting Reading Performance? http://uww.ehow.com/info_8131482_factors_affecting_reading

Anderson, R.C (2004). Role of the readers schema in comprehension, learning and memory. In R.B. Ruddell, \& N.J. Unrau (Eds.). Theoretical models and processes of reading (5 $5^{\text {the }}$.) Newwark, DE: International Reading Association.

Ausubel, D.P (1960). The use of advance organizers in the learning and retention of meaningful verbal material.Journal of Education psychology.

Branford, J. D (2004). Schema activation and Schema acquisition: comments on Richard C. Anderson's remarks. In R.B Ruddel, N.J. Unrau (Eds). Theoretical models and process of reading (5thed.). new, avk, DE: International Reading Association, Inc.

Carr, G. N. (2010). The shallows: what the Internet is doing to our brains. New York: W.W.Norton. ISBN 0-393-07222-3. OCLC 449865498 (//www.worldcat.org/oclc/449865498)

Cresuel, J.W. (2009). Research Design: Qualitative, Quantitative and Mixed Methods Approach (3rded). London: Sage publications Inc.

Daniel, K.J and SPED, P (2005): Advance organizers: Activating and building schema for more successful learning in students with disabilities. Lynchburg college: Kmdanz@netscape.com.

Eisenwine, M.J (2000). Visual memory and context cues in reading instruction.Journal Curriculum and Supervision, 15.Retrieved October 11, 2005 from Wilson Web database.Ekpu, F. S. (2005).Analysis of relevance of reading in health education.Journal of Applied Literacy and Reading 2. Port Harcourt: Double Diamond Publications.

Grasser, A, Golding, J. M, \& Long, D. L (1991).Narrative representation and comprehension. In R. Barr, M. L. Kamil, P. Mosenthal, and P. D Pearson (eds). Handbook of Reading Research (Vol 2 pp 171-204). White Plains, N Y: Longman.

Hassard, J. (2005) 2.10 Meaningful learning model.In the art of teaching science.http://scied.gsu.edu/Hassard/mos/2.10.html. Imam, H. (2004). Literacy and Readership: A Survey of Reading Habits of Education Students in the University of Abuja. Literacy and Reading in Nigeria. 10(1):205-212.

Kalmes, M. (2005).The advance organizer. In EDU 462: Methods in secondary social science. Retrieved November 13, 2005 from http://abraham.cuaa.edu/kalmesm/462s03/proc/advorg.htm

Maduabuchi C.H (2005). Graphic organizers and scaffolding strategies: enhancement tools for comprehension of expository and narrative texts. In Journal of Applied literacy and Reading. Double Diamond publications: Port Harcourt.

Matthew M. Thomas, Anthony V.; Manzo \& Casale, U. (2005).Content area literacy: strategicteaching for strategic learning. New York: Wiley. pp. 163-4. ISBN 0-471-15167-X. OCLC 58833339 (//www.worldcat.org/oclc/58833339)

Omojuwa, J. (2005). Laying a strong foundation for higher level reading achievements: Problems and Prospects.Journal of Applied Literacy and Reading, 2, 7 - 8. Port Harcourt: Double Diamond Publications.

Shen, Z. (2004). Effects of previewing and providing background knowledge on EFL reading comprhension of American documentary narratives. TESL Reporter.

Pressley M. (2007). Hand book of Reading Research Volume III http://www.readingonline.org/articles /handbooks/pressley/ .

Pressly, M \& El-Dinary, P. B. (1997). What we know about translating comprehension strategies instruction research into practice. Journal of Learning Disabilities, 30.

Pulido, D. (2004). The relationship between text comprehension and second language incidental vocabulary acquisition: A matter of topic familiarity? Language Learning, 54(3).

Potter, H. (2011). Reading Habits in Children. www.copperwiks.org/index.http://www.readingonline.org/articles /handbooks/pressley/.

Trochim, W.M (2005). The Research Methods (net)/kb/contents. Htm. 
Udosen, A. E. \& Ukpak, A. (2005).Reading readiness as a way of repositioning the individual.Journal of Applied Literacy and Reading 2 , 36. Port Harcourt: Double Diamond Publications. 